\title{
Enhanced Hot Salt-Water Corrosion Resistance of NiCoCrAlY-AlSiY Coating by Ion-Beam-Assisted Deposition
}

\author{
Guanming Xue ${ }^{1,+} \mathbb{D}$, Zhiguo Wang ${ }^{1,+}$, Enlei Wang ${ }^{1, *}$, Yan Tang ${ }^{2}$, Yanhui Zhao ${ }^{3}$, Yihe Wang ${ }^{1, *}$, Suying Hu ${ }^{1}$, \\ Lin Xiang ${ }^{2}$ and Zhiwen Xie ${ }^{1}$
}

1 Liaoning Key Laboratory of Complex Workpiece Surface Special Machining, University of Science and Technology Liaoning, Anshan 114051, China; xueguanming0812@126.com (G.X.); w13604864782@126.com (Z.W.); husuying@ustl.edu.cn (S.H.); xzwustl@126.com (Z.X.)

2 Precision Forming Center, Southwest Technology and Engineering Research Institute, Chongqing 400039, China; tyscsn@126.com (Y.T.); xlin0731@163.com (L.X.)

3 Institute of Metal Research, Chinese Academy of Sciences, Shenyang 110016, China; yhzhao@imr.ac.cn

* Correspondence: enleiwang@ustl.edu.cn (E.W.); wyhustl@126.com (Y.W.); Tel.: +86-412-5928267 (E.W.); +86-412-5929746 (Y.W.)

+ The authors contributed equally to this work.

check for updates

Citation: Xue, G.; Wang, Z.; Wang, E.; Tang, Y.; Zhao, Y.; Wang, Y.; Hu, S.; Xiang, L.; Xie, Z. Enhanced Hot Salt-Water Corrosion Resistance of NiCoCrAlY-AlSiY Coating by Ion-Beam-Assisted Deposition. Coatings 2021, 11, 1062. https:// doi.org/10.3390/coatings11091062

Academic Editor: Alexander D

Modestov

Received: 12 August 2021

Accepted: 29 August 2021

Published: 2 September 2021

Publisher's Note: MDPI stays neutral with regard to jurisdictional claims in published maps and institutional affiliations.

Copyright: (c) 2021 by the authors. Licensee MDPI, Basel, Switzerland. This article is an open access article distributed under the terms and conditions of the Creative Commons Attribution (CC BY) license (https:// creativecommons.org/licenses/by/ $4.0 /)$.

\begin{abstract}
A promising ion-beam-assisted deposition (IBAD) method was developed to improve the salt-water corrosion resistance of NiCoCrAlY-AlSiY coating. During hot salt-water exposure, hydrochloric acid $(\mathrm{HCl})$ was produced when chloride salt, water, and metal oxide reacted with each other, while $\mathrm{HCl}$ was also produced when chlorine reacted with water. The as-deposited AlSiY layer exhibited a loose texture accompanied by numerous pore defects, which triggered the multi-scale diffusion of $\mathrm{HCl}$, resulting in the large-area corrosion degradation of the coating texture and the rapid diffusion of the NiCoCrAlY bonding layer. By contrast, the ion-beam-assisted AlSiY layer showed a dense texture that effectively inhibited the inner diffusion of $\mathrm{HCl}$ and suppressed the corrosion reactions as well as the diffusion of the NiCoCrAlY bonding layer. The current results confirmed the significant potential of IBAD in inhibiting corrosion damage and diffusion of thermal protective coatings.
\end{abstract}

Keywords: thermal protective coatings; ion-beam-assisted deposition; corrosion; diffusion

\section{Introduction}

Given the continuous development of advanced aero-engines in recent years, thrustweight ratio is one of the key performance factors of aero-engines. Replacing nickel-based superalloys with lightweight and high-strength materials has proven to be effective for achieving high thrust and low mass requirements [1]. Titanium alloy, as a light metal material, is widely used in aero-engines because of its advantages of low density and good corrosion resistance [2-4]. Although titanium alloys exhibit certain thermal stability and corrosion resistance, when aero-engines are used in marine environments, they are affected by oxidation erosion as well as corrosion induced by hot salt mixtures and water vapor $[5,6]$. This process causes severe corrosion damage and degradation to the titanium alloy. From the perspective of marine corrosion prevention and aero-engine control, surface functional coating is currently one of the most economical and effective protection strategies.

$\operatorname{MCrAlY}(\mathrm{M}=\mathrm{Ni}$ and-or $\mathrm{Co})$ coatings and aluminate coatings exhibit high resistance to oxidation and hot corrosion. Aluminum in the coating forms an oxide layer that protects the underlying components [7-9]. When the amount of aluminum in the coating depletes gradually as the aluminum oxide layer further develops and peels off, the coating becomes degraded and fails. However, directly increasing the Al content reduces the plasticity of the coating. This above issue is resolved by designing composite coatings with multiple layers or gradient structures [10,11]. Jiang et al. [12] synthesized MCrAlY+AlSiY composite 
coatings using arc ion plating (AIP). These gradient structure coatings exhibited good anti-oxidation and anti-corrosion properties. In the temperature range of $700-1050{ }^{\circ} \mathrm{C}$, they could adequately protect the superalloy matrix under various working conditions and effectively increase their service time [13-15]. Due to the excellent performance of this coating system, researchers have conducted a lot of research into this aspect. They discovered that an aluminide coating co-modified with Si and Y greatly ameliorated the resistance of the matrix to hot corrosion. The doped $\mathrm{Si}$ enhanced the resistance to hot corrosion of aluminide coating due to the formation of a $\mathrm{SiO}_{2}$ scale. By adding a small amount of $Y$ to the aluminide coating, it can promote the selective oxidation of $\mathrm{Al}$ and improve the adhesion of the $\mathrm{Al}_{2} \mathrm{O}_{3}$ layer [16-18]. However, these AIP coatings exhibited a loose texture with numerous pores. These defects provided pathways for the diffusion of oxygen and aggressive media, therefore significantly degrading their corrosion resistance [19].

Ion-beam-assisted deposition (IBAD) has been discovered to be an effective method for improving the compactness of coatings. Jung et al. [20] reported that IBAD induced an enhanced packing of sputtering atoms, resulting in a dense and more adhesive interlayer. Mao et al. [21] reported that IBAD effectively decreased the film cavity, therefore resulting in a dense growth texture. The principle of IBAD for improving the coating density is similar to that of the deposition process, in which high-energy bombardment ions collide with the deposited atoms; consequently, a significant amount of energy is transferred to the deposited atoms, and the atoms are simulated to move horizontally and longitudinally. The movement of the atoms fills the cavity of the coating and generates a dense coating [22,23].

In this investigation, as-deposited and ion-beam-assisted NiCoCrAlY-AlSiY coatings were synthesized on Ti6Al4V alloys. The hot salt-water corrosion behaviors of these coatings were characterized to clarify the effects of IBAD on structure and properties of these coatings, and the hot salt-water synergistic corrosion mechanisms are discussed comprehensively.

\section{Materials and Methods}

$\mathrm{Ti}_{6} \mathrm{Al}_{4} \mathrm{~V}$ alloy was used as the substrate. The sample size was $10 \times 10 \times 5 \mathrm{~mm}^{3}$. All samples were sandblasted using corundum grits and further cleaned in alcohol. The coatings were synthesized using AIP and arc-enhanced glow discharge (AEGD). $\mathrm{Ni}_{39.5} \mathrm{Co}_{26} \mathrm{Cr}_{22} \mathrm{Al}_{12} \mathrm{Y}_{0.5}$ and $\mathrm{Al}_{89} \mathrm{Si}_{10} \mathrm{Y}_{1}$ (wt.\%) were used as the arc targets. All the samples were cleaned using AEGD. The parameters involved were $0.3 \mathrm{~Pa}$ Ar pressure, $100 \mathrm{~A}$ current, $-160 \mathrm{~V}$ bias voltage, and $30 \mathrm{~min}$ time. Table 1 presented the parameters of the NiCoCrAlY-AlSiY coatings. To enhance the anti-corrosion performance of the top AlSiY layer, AEGD was employed to produce high-density electrons, which triggered the Ar atom ionization. The enhanced Ar ion-beam-assisted deposition (IBAD) greatly improved the density of the AlSiY layer. In this work, sample E1 corresponded to the NiCoCrAlY-AlSiY coating without the IBAD, while sample E2 was the NiCoCrAlY-AlSiY coating with the IBAD. AEGD current was $100 \mathrm{~A}$.

Table 1. Experimental details of all coatings.

\begin{tabular}{ccc}
\hline Parameters & NiCoCrAlY Layer & AlSiY Layer \\
\hline Arc current (A) & 105 & 75 \\
Bias voltage (V) & -150 & -110 \\
Time (min) & 200 & 105 \\
\hline
\end{tabular}

A muffle furnace was used for the salt-water corrosion experiment. The water vapor was transferred to the muffle furnace (Shenyang ElectricFurnace Factory, Shenyang, China) through a water-vapor generator (Anhui Kangxin Electric Appliance Company, Anhui, China). The volume percentage of water vapor was approximately $47 \%$ during the entire experiment. The experiment was carried out by coating mixed salt on the surface. Before starting the test, all samples were preheated to about $100{ }^{\circ} \mathrm{C}$ in an electric furnace 
(Huxing Electric Heating Appliance Factory, Jiangsu, China); subsequently, the samples were uniformly sprayed with a salt-mixture aqueous solution containing $75 \mathrm{wt} . \% \mathrm{Na}_{2} \mathrm{SO}_{4}$ $+25 \mathrm{wt} . \% \mathrm{NaCl}$. To prevent the salt film from being unevenly covered, the salt coating process was carried out several times to ensure that the salt content of the samples was $2-3 \mathrm{mg} / \mathrm{cm}^{2}$. The temperature of this experiment was $650{ }^{\circ} \mathrm{C}$ and the duration was $200 \mathrm{~h}$. The heating rate of this experiment was controlled at $8-10{ }^{\circ} \mathrm{C} / \mathrm{min}$. To plot the corrosion kinetics curves, all samples were weighed at 20-h intervals during the first $100 \mathrm{~h}$ of the test and at 50-h intervals between 100-200 h using a balance (Shanghai Sunny Hengping Scientific Instrument Company, Shanghai, China) with an accuracy of $0.0001 \mathrm{~g}$. Before weighing, the samples were washed more than three times in boiling deionized water until the water was clear and almost free of impurities. To eliminate the error of mass measurement, samples E1 and E2 were measured with three sets of parallel specimens, and the average value was taken as the measurement result.

The surface-phase compositions of samples E1 and E2 after the corrosion experiments were detected via X-ray diffraction (XRD, X' Pert Powder, PANalytical B.V., Almelo, The Netherlands ). The radiation source was $\mathrm{Cu}-\mathrm{K} \alpha$, the scanning range was $10^{\circ}-90^{\circ}$, and the scanning time was $2 \mathrm{~min}$. The surface and cross-sectional images of as-deposited and corroded samples were characterized via scanning electron microscopy (SEM, Zeiss ¿IGMA HD, Carl Zeiss, Jena, Germany). To avoid the spalling of the corrosion layer of the sample during the preparation of the cross-sectional sample for SEM, a nickel layer was fabricated on the AlSiY layer via electroplating. The nickel-plated samples were embedded in epoxy resin, and the sections were abraded with 180-, 320-, 600-, 1200-, and 2000-mesh SiC sandpaper and polished with diamond polishing paste. The samples were then cleaned with anhydrous ethanol and dried. The compositions of the corroded samples were determined using an energy-dispersive spectrometer equipped on the SEM.

\section{Results}

Figure 1 presents the XRD patterns of the as-deposited coatings. Since the two samples used the same matrix and target during the deposition of the coating, IBAD technology mainly changed the texture of the coating and had little effect on the composition of the coating, so samples E1 and E2 exhibited similar phase structures. For these two composite coatings, the diffraction peaks detected by XRD were primarily located at the outermost side of the AlSiY layer, and the content of silicon and yttrium was less in the AlSiY layer, these strong diffraction peaks were assigned to the $\mathrm{Al}$ phases and the number of Si-phase diffraction peaks that could be detected is small and the intensity is low, while the $Y$ diffraction peak could hardly be detected $[11,18]$. The XRD results clearly indicated that the phase composition of the two samples was consistent with the target material used for deposition, and there are no other impurities.

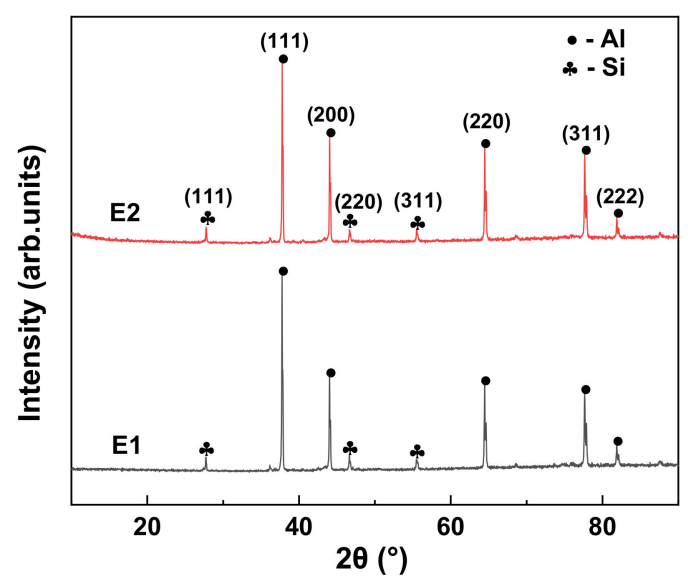

Figure 1. XRD results of the as-deposited coatings. 
Figure 2 presents the surface and cross-sectional SEM images of all coatings. Sample E1 exhibited a rough surface, as shown in Figure $2 a$, where numerous particles and pores were observed, as well as deeper holes (see high-magnification images). Additionally, numerous pores and loose textures were observed in the cross-sectional images of Figure $2 b$. The aggregation of holes, cracks, and large particles in the coating was observed in the high-magnification cross-section image inserted in Figure $2 \mathrm{~b}$. These structures were widely distributed in the AlSiY layer, which resulted in the low density of this layer. By contrast, sample E2 exhibited a relatively smooth and dense texture topography, as shown in Figure 2c. Additionally, the size and number of such particles and pores decreased significantly, whereas a local dense texture and smaller pores were observed in the cross-sectional image presented in Figure $2 \mathrm{~d}$, including in the high-magnification cross-sectional images. Only a few small pores and particles were observed in the AlSiY layer, which is consistent with the flat and dense surface morphology revealed. Meanwhile, compared with the AlSiY layer deposited by traditional arc ion plating, the structure density and the number of large particles of the AlSiY layer of sample E2 were significantly improved, indicating that the IBAD significantly enhanced the compactness of the top AlSiY layer [15,19,24].
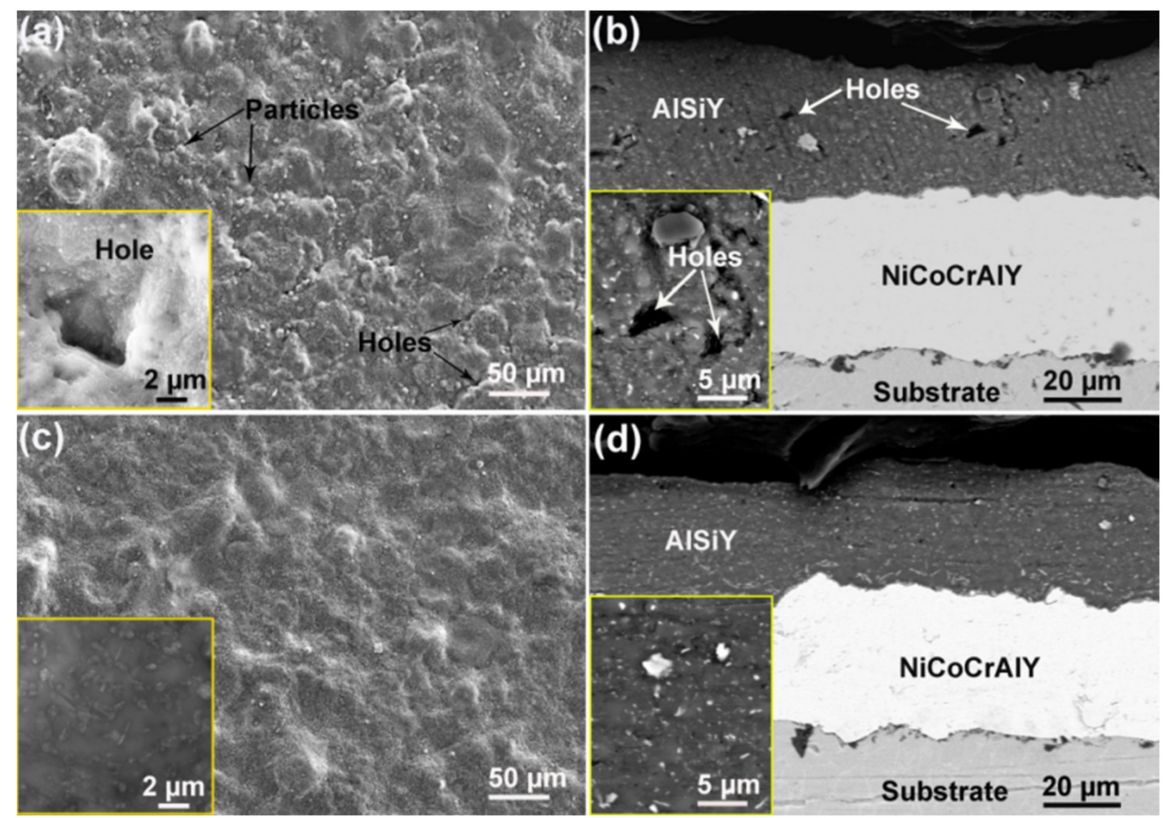

Figure 2. Surface and cross-sectional images of samples E1 (a,b) and E2 (c,d).

Figure 3 presents the corrosion kinetics curves of samples E1 and E2 during the experiments. During the first $40 \mathrm{~h}$ of corrosion, two samples underwent a stage of rapid quality growth. Subsequently, the mass growth rate of sample E1 decelerated, but it maintained a weight-gain trend until the end of the test. The weight-gain rate of sample E2 decreased significantly from 40-60 h and the kinetic curve exhibited a downward trend after $60 \mathrm{~h}$, indicating that the sample experienced continuous weightlessness and the mass loss ceased until $100 \mathrm{~h}$. Subsequently, the kinetic curve was relatively flat until the end of the test. After $200 \mathrm{~h}$ of testing, the mass gains of samples E1 and E2 were $1.95 \mathrm{mg} / \mathrm{cm}^{2}$ and $20.25 \mathrm{mg} / \mathrm{cm}^{2}$, respectively. During the whole test process, sample E2 showed a higher corrosion mass gain, but both samples showed a mass gain after the test. Compared with our previous study, destructive spalling occurred on the surface of Ti6Al4V after $200 \mathrm{~h}$ under the same test conditions, and the corrosion dynamics curve showed serious mass loss [6]. This indicated that there was no devastating corrosion degradation in the coating system of the two samples in this test and they could still protect the substrate, so the higher corrosion weight cannot indicate poor corrosion resistance of the sample. The differences in the corrosion dynamics curves of the two samples are described in detail in the following section. 


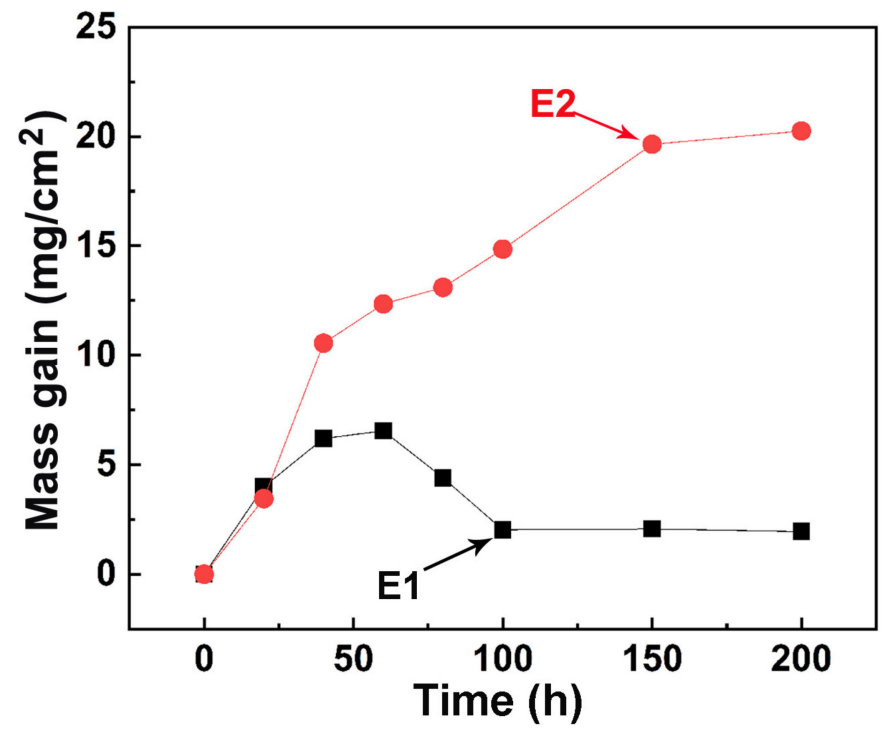

Figure 3. Corrosion kinetics curves of samples E1 and E2 during the corrosion experiments.

Figure 4 presents the XRD patterns of samples E1 (a) and E2 (b) after hot salt-water corrosion experiments. During $200 \mathrm{~h}$ of corrosion, the phase composition of the two samples, which was primarily composed of $\mathrm{Al}_{2} \mathrm{O}_{3}$ and $\beta-(\mathrm{Ni}, \mathrm{Co}) \mathrm{Al}$ phases, did not change significantly; this indicates that oxide film grown on the coating surface of all samples was single $\mathrm{Al}_{2} \mathrm{O}_{3}$ during the entire hot salt-water corrosion tests. The appearance of the $\beta-(\mathrm{Ni}, \mathrm{Co}) \mathrm{Al}$ phase indicates that interdiffusion occurred in the AlSiY and NiCoCrAlY layers during the test [12-14]. After $200 \mathrm{~h}$ of hot salt-water corrosion testing, the diffraction peak of the $\beta-(\mathrm{Ni}, \mathrm{Co}) \mathrm{Al}$ phase was strong, and the $\gamma-\gamma^{\prime}$ phase was not detected. It can be inferred that at the end of the test, the content of aluminum in the AlSiY layer of the composite coating remained high, and that it can continue to provide protection to the substrate by generating $\mathrm{Al}_{2} \mathrm{O}_{3}$.
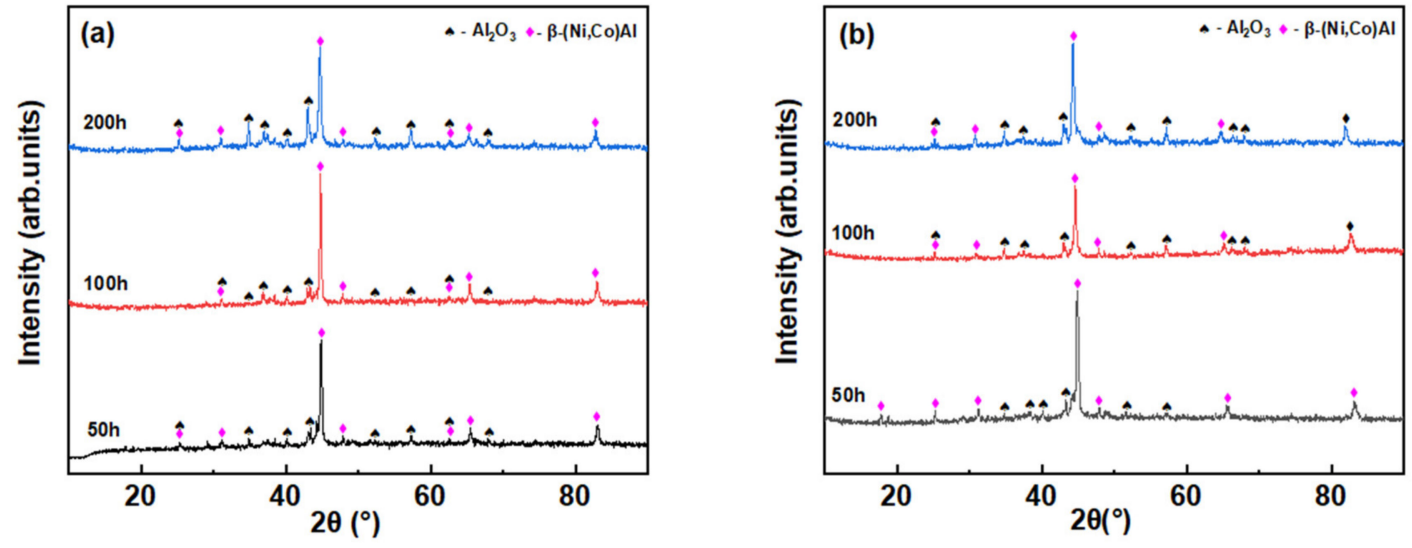

Figure 4. XRD patterns of samples E1 (a) and E2 (b) after hot salt-water corrosion experiments.

Figure 5 shows the cross-sectional images of hot salt-water-corroded coatings. An oxide layer was grown on the coating surface of the E1 sample, and the thickness of the oxide layer was approximately $20 \mu \mathrm{m}$, as shown in Figure 5a; the oxide layer, which was loose and porous, indicated poor interfacial adhesion with the AlSiY layer. Under the oxide layer, a large area containing corrosion holes was formed in the AlSiY layer, and some internal corrosion products appeared in the holes. As shown in Figure 5b, after $100 \mathrm{~h}$ of corrosion, the area containing corrosion holes in the AlSiY layer of sample E1 expanded, and the number of holes increased. The maximum depth of the corrosion-hole damage zone was $48 \mu \mathrm{m}$, which almost penetrated the entire AlSiY layer. When the $200 \mathrm{~h}$ 
of corrosion was complete, some adjacent corrosion holes in sample E1 aggregated to form a larger corrosion area, as shown in Figure 5c. Numerous small internal corrosion pores appeared near the corrosion holes as well as at the AlSiY-oxide layer interface in the AlSiY layer, and the corrosion holes were filled with a significant amount of corrosion products. The crack generated from the bottom of the corrosion hole extended into the NiCoCrAlY layer. Compared with sample E1, sample E2 indicated only slight corrosion damage, as presented in Figure 5d,e. Small corrosion holes were observed in the damage regions, and their size and quantity did not increase significantly during corrosion. After $200 \mathrm{~h}$ of corrosion, the oxide layer of sample E2 was slightly peeled off, as presented in Figure 5f; however, compared with sample E1, the internal corrosion holes in sample E2 were less dense, and the distribution depth was shallow. Additionally, the NiCoCrAlY layer of sample E1 was thinner, indicating significant diffusion. By contrast, sample E2 indicated a relatively low diffusion rate, as reflected by the barely changing thickness of the $\mathrm{NiCoCrAlY}$ layer. In the previous studies, we found that when water vapor participated in the hot corrosion test, it would have a synergistic effect with salt at high temperature, leading to more severe corrosion degradation. Under the same test conditions, almost no complete oxide layers could be formed on the surface of Ti6Al4V substrate after $200 \mathrm{~h}$ of testing. The substrate was corroded seriously, resulting in the formation of a large area of corrosion holes [6]. In this test, the substrates of the two samples were not obviously corroded, indicating that the coatings of the two samples had a good protective effect on the substrates.
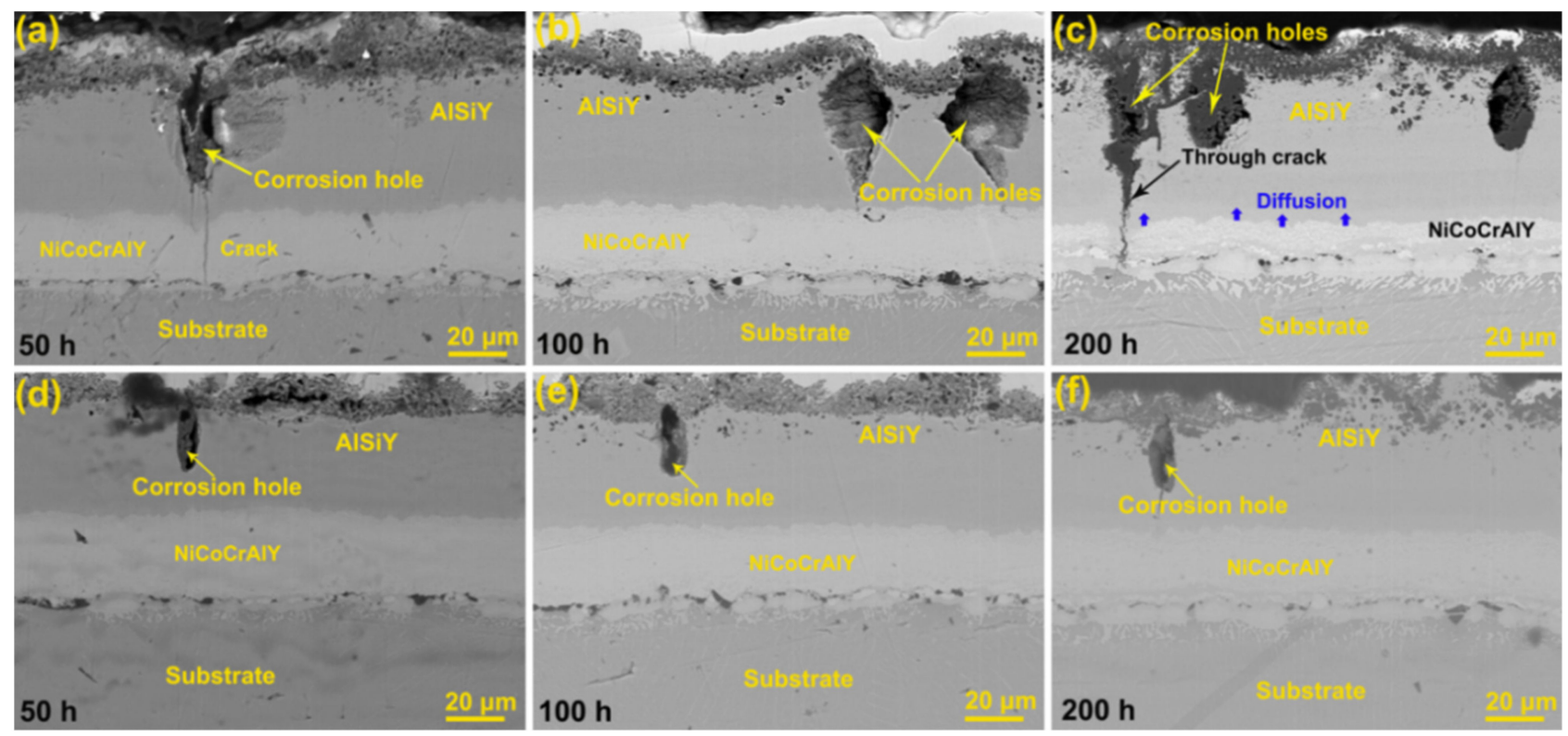

Figure 5. SEM cross-sectional images of the corroded samples E1 (a-c) and E2 (d-f).

Figure 6 shows the cross-sectional SEM images and the element mappings of the hot salt-water corroded sample E1. Based on the XRD results with element mappings of $\mathrm{Al}$ and $\mathrm{O}$, the main composition of the oxide layer was alumina. Furthermore, the amounts of $\mathrm{Al}$ and $\mathrm{O}$ in the corrosion holes and internal corrosion pores increased, indicating that the corrosion products were primarily composed of $\mathrm{Al}_{2} \mathrm{O}_{3}$. In addition, it was observed that the $\mathrm{Ni}, \mathrm{Co}$, and $\mathrm{Cr}$ in the NiCoCrAlY layer diffused into the AlSiY layer, which contributed to the $\beta-(\mathrm{Ni}, \mathrm{Co}) \mathrm{Al}$ phase in the XRD pattern. It is noteworthy that there is a Cr-rich layer at the interface between the NiCoCrAlY layer and the substrate. It is reported that the Cr-rich layer can serve as a diffusion barrier to prevent the mutual diffusion of the beneficial elements in the coating and the refractory elements in the matrix [24]. Based on element mapping, it was discovered that the $\mathrm{Ti}$ in the substrate almost did not diffuse into the coating, while the diffusion of elements in the NiCoCrAlY layer to the substrate was 
relatively slight, indicating that the $\mathrm{Cr}$-rich layer effectively inhibited the mutual diffusion of elements between the coating and substrate.
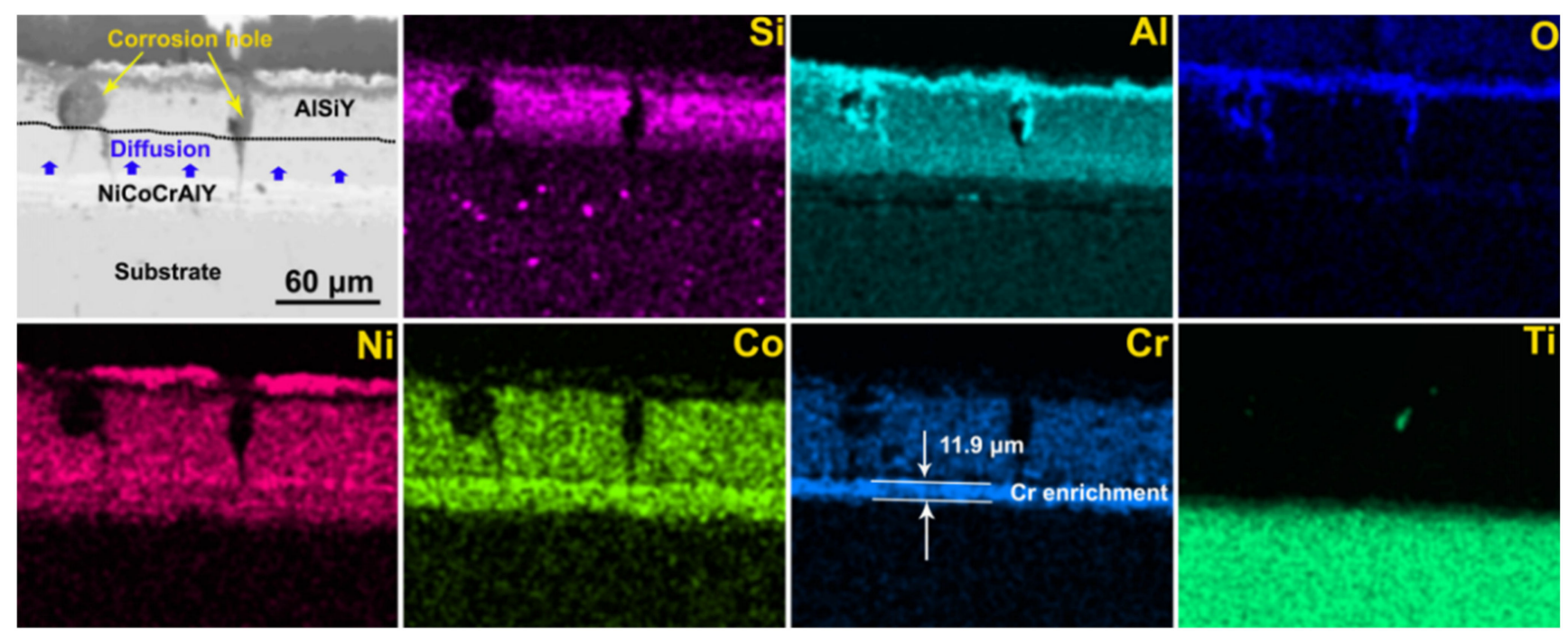

Figure 6. Cross-sectional images and element mappings of hot salt-water-corroded sample E1.

Figure 7 shows the cross-sectional SEM images and the element mappings of hot saltwater-corroded sample E2. Compared with sample E1, some areas of sample E2 exhibited a thicker oxide layer, and regions where the amounts of $\mathrm{Cr}$ and $\mathrm{Si}$ increased were discovered to be underneath the oxide layer. Only a very small amount of $\mathrm{Cr}$ and $\mathrm{Si}$ can be dissolved in the $\beta-(\mathrm{Ni}, \mathrm{Co}) \mathrm{Al}$ phase. Therefore, the formation of the element enrichment region reflects the AlSiY layer of the E2 sample containing more $\beta$-(Ni, Co)Al content, which in fact resulted in the segregation of $\mathrm{Cr}$ and $\mathrm{Si}$ to form a $\mathrm{Cr}-\mathrm{Si}$ phase. It has been reported that the $\mathrm{Cr}-\mathrm{Si}$ phase can inhibit corrosion $[12,19]$. Based on element mapping, the distribution depth of the Al-rich region in sample E2 was deeper than that in sample E1, indicating a significantly lower consumption of $\mathrm{Al}$ in sample E2. Meanwhile, the Cr-rich layer formed at the NiCoCrAlY layer-TC4 interface of sample E2 was thicker, which indicates that its element diffusion rate was lower during the corrosion.
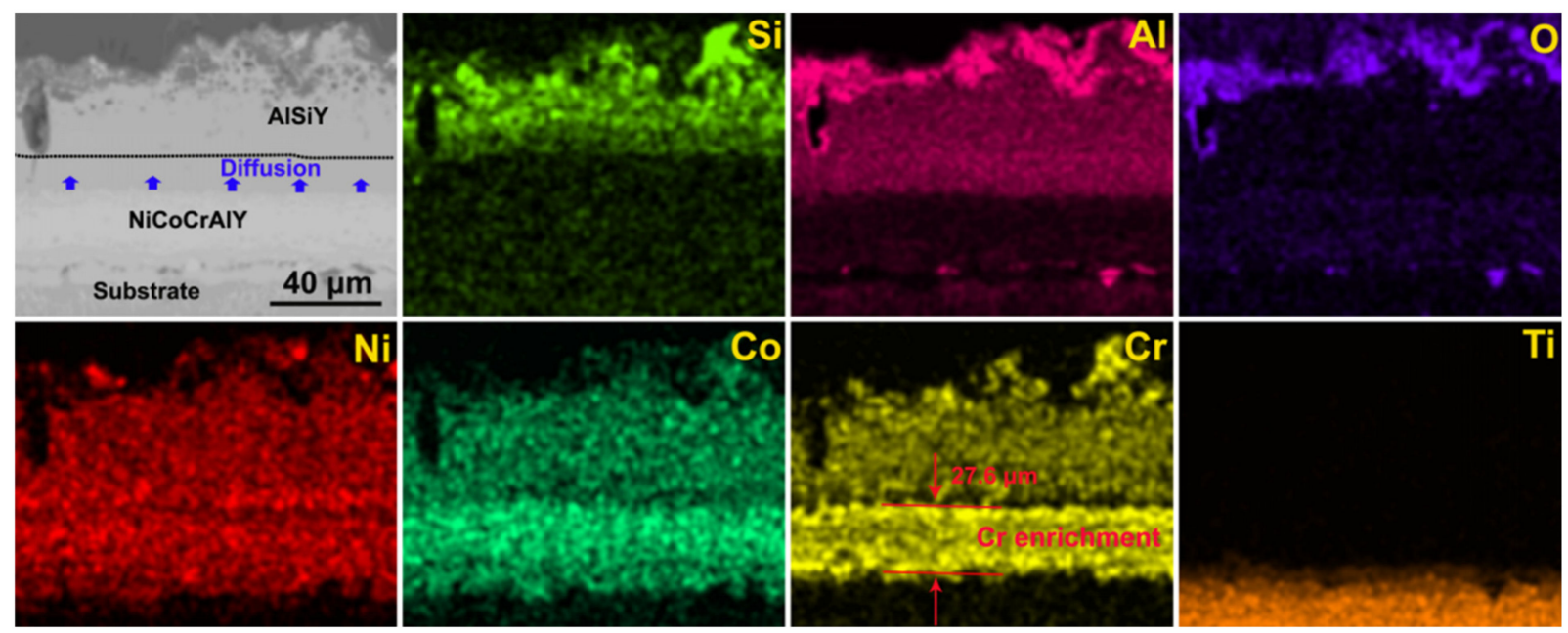

Figure 7. Cross-sectional images and element mappings of hot salt-water-corroded sample E2.

Samples E1 and E2 have the same coating system and chemical composition; however, their corrosion degrees differed significantly in the whole test, which indicates the importance of the effect of the IBAD technique on the texture of the AlSiY layer in improving hot 
corrosion resistance. The feasible explanation for the hot salt-water corrosion mechanisms of the two samples is illustrated in Figure 8. Compared with the traditional hot salt corrosion test, the synergistic action of oxygen-mixed salt-water vapor at high temperature resulted in a more severe corrosion damage to the coating system. The damage process could be divided into two stages, which primarily included the initial degradation of the oxide layer and the accelerated destruction of the metal coating. As shown in Figure 8a,c, at the beginning of the test, the amount of $\mathrm{Al}$ in the AlSiY layer was high, which promoted the selective oxidation of $\mathrm{Al}$ (as expressed by Equation (1)), and an $\mathrm{Al}_{2} \mathrm{O}_{3}$ layer grown rapidly on the surface of this coating. Additionally, the synergistic effect of water vapor and the deposited salt mixture resulted in the degradation reaction of the $\mathrm{Al}_{2} \mathrm{O}_{3}$ layer (as expressed by Equation (2)), which resulted in the degradation of a portion of $\mathrm{Al}_{2} \mathrm{O}_{3}$ into $\mathrm{NaAlO}_{2}$ and $\mathrm{HCl}[25,26]$.

$$
\begin{gathered}
4 \mathrm{Al}+3 \mathrm{O}_{2}=2 \mathrm{Al}_{2} \mathrm{O}_{3} \\
2 \mathrm{NaCl}+\mathrm{Al}_{2} \mathrm{O}_{3}+\mathrm{H}_{2} \mathrm{O}=2 \mathrm{NaAlO}_{2}+2 \mathrm{HCl}
\end{gathered}
$$

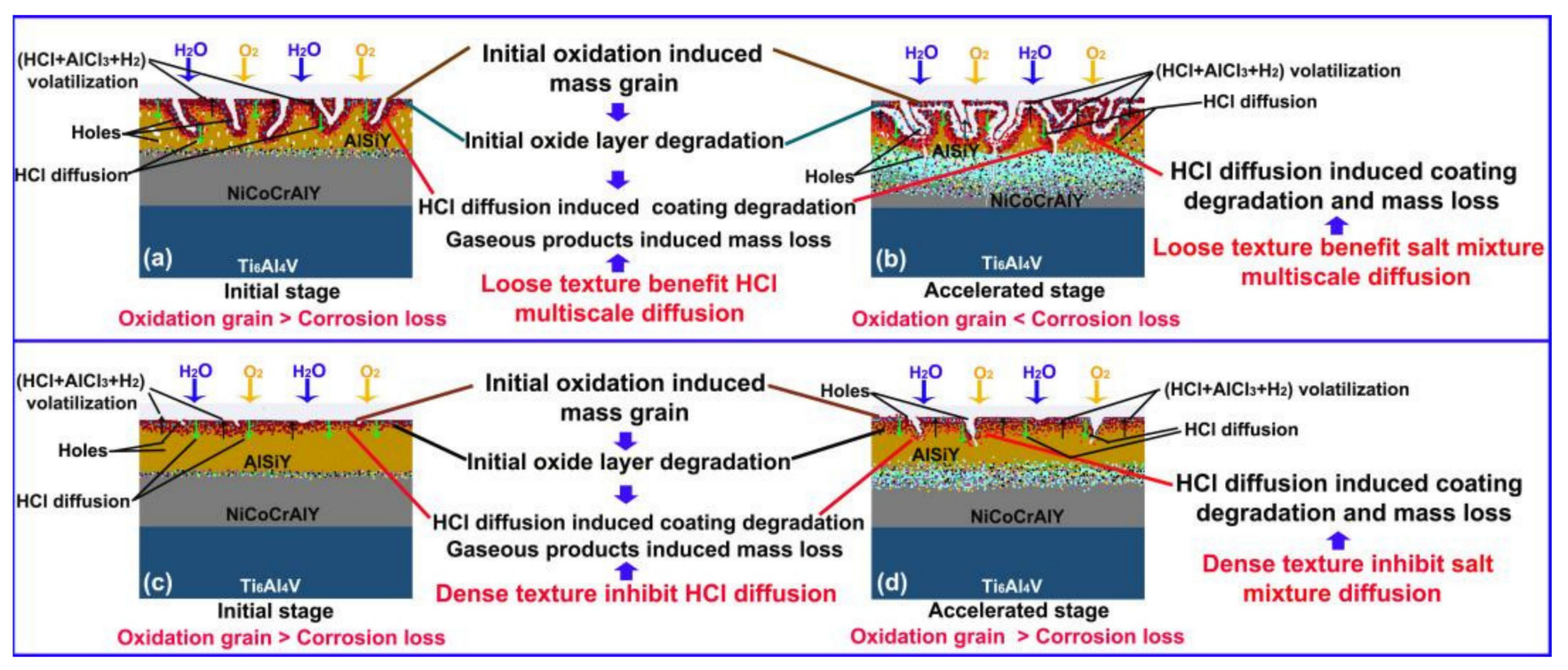

Figure 8. Schematic of hot corrosion mechanism of samples E1 (a,b) and E2 (c,d).

Therefore, the oxide layer exhibited a loose and porous structure at the initial stage of corrosion, which resulted in its insufficient protective effect. $\mathrm{HCl}$ can diffuse rapidly into the coating through the oxide layer and react with $\mathrm{Al}$ in the coating to generate gaseous $\mathrm{AlCl}_{3}$ and $\mathrm{H}_{2}$ based on Equation (3), resulting in further degradation of the coating.

$$
2 \mathrm{Al}+6 \mathrm{HCl}=2 \mathrm{AlCl}_{3}+3 \mathrm{H}_{2}
$$

During corrosion, the coating enters the accelerated degradation stage, as shown in Figure $8 b$,d. The mixed salt comprising $\mathrm{Na}_{2} \mathrm{SO}_{4}$ and $\mathrm{NaCl}$ diffuses into the coating through the pores of the oxide layer, and a eutectic reaction occurs based on Equations (4) and (5), followed by a decomposition process [19].

$$
\begin{gathered}
2 \mathrm{NaCl}+\mathrm{SO}_{2}+\mathrm{O}_{2}=\mathrm{Na}_{2} \mathrm{SO}_{4}+1 / 2 \mathrm{Cl}_{2} \\
\mathrm{Na}_{2} \mathrm{SO}_{4}=\mathrm{SO}_{3}+\mathrm{Na}_{2} \mathrm{O}=\mathrm{Na}_{2} \mathrm{O}+1 / 2 \mathrm{O}_{2}+\mathrm{SO}_{2}
\end{gathered}
$$

When the mixed salt composition is $\mathrm{NaCl}$ and $\mathrm{Na}_{2} \mathrm{SO}_{4}, \mathrm{NaCl}$ will react with $\mathrm{O}_{2}$ and $\mathrm{SO}_{2}$ generated by the decomposition of $\mathrm{Na}_{2} \mathrm{SO}_{4}$ to release chlorine; subsequently, chlorine will react with water vapor to produce $\mathrm{HCl}$ and $\mathrm{HClO}$. Unstable $\mathrm{HClO}$ will decompose at high temperatures, leading to the formation of $\mathrm{HCl}$ and $\mathrm{O}_{2}$ based on Equations (6) and (7). 
$\mathrm{O}_{2}$ and $\mathrm{HCl}$ react with $\mathrm{Al}$ in the coating to form $\mathrm{Al}_{2} \mathrm{O}_{3}$ and $\mathrm{AlCl}_{3}$ (see Equations (1) and (3)), resulting in significant internal oxidation and internal corrosion in the coating.

$$
\begin{gathered}
\mathrm{Cl}_{2}+\mathrm{H}_{2} \mathrm{O}=\mathrm{HCl}+\mathrm{HClO} \\
2 \mathrm{HClO}=2 \mathrm{HCl}+\mathrm{O}_{2}
\end{gathered}
$$

Based on the above discussion of the corrosion mechanism, the differences in the morphology of the two samples during the test were analyzed, and the findings obtained were as follows: holes, cracks, and large particles were widely distributed in the AlSiY layer of the as-deposited sample E1. At the beginning of the test, the oxide layer was not fully formed, and the defects became the diffusion path for oxygen to diffuse into the AlSiY layer, and promote the internal oxidation of the AlSiY layer to generate $\mathrm{Al}_{2} \mathrm{O}_{3}$, which primarily accumulated in the holes and cracks inside the coating. $\mathrm{Al}_{2} \mathrm{O}_{3}$ decomposed by reacting with $\mathrm{NaCl}$ and $\mathrm{H}_{2} \mathrm{O}$; therefore, the oxide layer on the $\mathrm{AlSiY}$ layer first decomposed and produced numerous holes to provide a pathway for the diffusion of $\mathrm{NaCl}$ and $\mathrm{H}_{2} \mathrm{O}$ into the interior of the coating, therefore resulting in the decomposition of $\mathrm{Al}_{2} \mathrm{O}_{3}$ inside the coating. The $\mathrm{HCl}$ generated by the decomposition of $\mathrm{Al}_{2} \mathrm{O}_{3}$ reacted with $\mathrm{Al}$ in the coating, which caused a significant reaction degradation in the AlSiY layer. By contrast, as IBAD technology improves the structural density of the AISiY layer in the as-deposited sample E2, most of the holes and cracks in the coating were eliminated, which significantly reduced the size of the internal defects in the coating. Therefore, in the initial stage of hot corrosion, the oxidation reaction on the coating surface of sample E2 was the main cause of corrosion. The smaller internal hole size inhibited the internal oxidation of the AlSiY layer, the formation and diffusion of $\mathrm{HCl}$ in the coating were further restrained, and the coating was only slightly corroded and degraded.

In the middle and late stages of corrosion, the eutectic reaction and decomposition of the mixed salt resulted in the formation of numerous corrosive media. Owing to the severe corrosion damage of sample E1 after the initial stage of corrosion, the oxide layer and the interior of the AlSiY layer exhibited a loose and porous structure, which resulted in the high diffusion rate of corrosive media. Severe internal corrosion and internal oxidation occurred in the AlSiY layer, which enlarged the corrosion holes in the coating and resulted in the generation of numerous small internal corrosion pores. The gaseous corrosion products generated by the internal corrosion of the AlSiY layer diffused outward through the oxide layer, and more cracks and pores appeared in the coating and oxide layer during this process. By contrast, the AlSiY layer of sample E2 exhibited only slight corrosion damage after the initial stage of corrosion, and the smaller corrosion holes significantly decelerated the diffusion of the corrosive media into the coating. Furthermore, the dense AlSiY layer can reduce the space for aggregation and reaction of the corrosive media in the coating. Therefore, during the entire corrosion process of sample E2, no significant internal corrosion occurred, and the corrosion area was primarily concentrated in the $\mathrm{Al}_{2} \mathrm{O}_{3}$ layer and the interface of the $\mathrm{Al}_{2} \mathrm{O}_{3}$ layer-AlSiY layer.

Based on the above analysis, the reasons for the differences in corrosion dynamics curves of the two samples were explained as follows: The change in corrosion mass is a comprehensive reflection of the growth, dissolution, and peeling of corrosion products in the coating system. At the beginning of the test, selective oxidation of Al mainly occurred, and an oxidation layer was rapidly generated on the surface of the AlSiY layer. Consequently, the corrosion kinetics curves of the two samples showed a rapid rising trend. Moreover, because of the many defects inside the AlSiY layer of sample E1, serious internal oxidation occurred at the same time; the mass gain of sample E1 in the first $20 \mathrm{~h}$ of corrosion was slightly higher than that of sample E2. As the test progressed, salt and water gradually participated in the corrosion. They reacted with the oxide layer on the surface of the coating and the internal oxide in the coating, resulting in the degradation of $\mathrm{Al}_{2} \mathrm{O}_{3}$, and the acidic corrosion products produced by the reaction react directly with $\mathrm{Al}$ in the coating to generate gaseous corrosion products, which directly dissolves the coating. 
This process causes serious mass loss in the sample. Since sample E1 experienced serious internal oxidation at the beginning of the test, and there were many internal defects in the AISiY layer, the above reaction was more violent in sample E1, resulting in relatively large corrosion mass loss. Therefore, after the first $20 \mathrm{~h}$ of corrosion, the mass gain trend of the corrosion kinetic curve of sample E1 decreased and gradually became flat. When the corrosion gradually entered the middle stage, the eutectic reaction and decomposition of the mixed salt led to the formation of a large amount of corrosive media. As mentioned above, the corrosive medium had a high diffusion rate in the AlSiY layer of sample E1, which led to serious internal corrosion, and the reaction mainly generated gaseous corrosion products. The massive volatilization of gaseous corrosion products led to extremely high mass loss of the sample E1. Thus, during the $60-100 \mathrm{~h}$ corrosion process, the corrosion kinetic curve of sample E1 showed a downward trend. During the 100-200 h corrosion process, the corrosion kinetics curve of sample E1 showed a flat state. When observing the SEM cross-sectional images, it can be found that the internal corrosion holes in the AlSiY layer were almost filled with oxide at $200 \mathrm{~h}$. It can be inferred that as the corrosion-hole area inside the AlSiY layer expands in the middle and late stages of the corrosion, the contact area between the coating and oxygen gradually increases. At this stage, the mass gain caused by the formation of an oxide layer on the surface of the AlSiY layer and the generation of the internal oxide of the coating was in dynamic balance with the mass loss caused by the corrosion degradation of oxide and the corrosion dissolution of the coating. By contrast, the AlSiY layer of sample E2 had good compactness and few defects, and no serious internal corrosion occurred during the entire corrosion process. The corrosion kinetics curve was mainly controlled by the formation and corrosion degradation of the oxide layer on the surface of the AlSiY layer, and low corrosion mass loss resulted in a continuous upward trend of the corrosion kinetics curve.

\section{Conclusions}

This study investigated the hot salt-water corrosion behaviors of as-deposited and ionbeam-assisted NiCoCrAlY-AlSiY coatings. Results showed that the as-deposited coating exhibited unsatisfactory corrosion resistance after a hot salt-water experiment. The numerous pores and the loose texture in the AlSiY layer provided multi-scale diffusion channels for the corrosive medium, therefore triggering large-area corrosion degradation on the coating texture and rapid elemental diffusion on the NiCoCrAlY layer. The ion-beam-assisted coating showed a significant enhancement in hot corrosion resistance after a hot salt-water experiment. The IBAD technique induced the formation of a dense growth texture in the AlSiY layer, which not only effectively prevented multi-scale diffusion of the corrosive medium, but also significantly inhibited the corrosion reaction and elemental diffusion of the NiCoCrAlY layer. The IBAD technique shows huge potential to enhance anti-corrosion performance of thermal protective coatings during hot salt-water environmental exposure.

Author Contributions: Conceptualization, E.W. and Y.W.; methodology, Y.T. and Z.W.; investigation, G.X. and L.X.; supervision, S.H., Y.Z. and Z.X. All authors have read and agreed to the published version of the manuscript.

Funding: This work was funded by Southwest Institute of Technology and Engineering Cooperation fund (HDHDW5902020103), University of Science and Technology Liaoning Talent Project Grants (601011507-07), Graduate Education Reform and Science and Technology Innovation Project of University of Science and Technology Liaoning (LKDYC202019).

Institutional Review Board Statement: Not applicable.

Informed Consent Statement: Not applicable.

Data Availability Statement: No new data were created or analyzed in this study. Data sharing is not applicable to this article.

Acknowledgments: We sincerely thank the Likui Ning for the coating deposition. 
Conflicts of Interest: The authors declare no conflict of interest.

\section{References}

1. Cai, J.M.; Cao, C.X. Alloy Design and application expectation of a new generation $600{ }^{\circ} \mathrm{C}$ high temperature titanium alloy. $J$. Aeronaut. Mater. 2014, 34, 27-36. [CrossRef]

2. Kim, S.W.; Hong, J.K.; Na, Y.S.; Yeom, J.T.; Kim, S.E. Development of TiAl alloys with excellent mechanical properties and oxidation resistance. Mater. Des. 2014, 54, 814-819. [CrossRef]

3. Appel, F.; Clemens, H.; Fischer, F.D. Modeling concepts for intermetallic titanium aluminides. Prog. Mater. Sci. 2016, 81, 55-124. [CrossRef]

4. Chen, G.; Peng, Y.; Zheng, G.; Qi, Z.; Wang, M.; Yu, H.; Dong, C.; Liu, C.T. Polysynthetic twinned TiAlsingle crystals for high-temperature applications. Nat. Mater. 2016, 15, 876-881. [CrossRef]

5. Ciszak, C.; Popa, I.; Brossard, J.-M.; Monceau, D.; Chevalier, S. NaCl-induced high-temperature corrosion of $\beta_{21}$ S Ti alloy. Oxid. Met. 2017, 87, 729-740. [CrossRef]

6. Wu, H.; Gong, P.; Hu, S. Hot corrosion damage mechanism of Ti6Al4V alloy in marine environment. Vacuum 2021, 191, 110350. [CrossRef]

7. Gheno, T.; Meier, G.H.; Gleeson, B. High temperature reaction of MCrAlY coating compositions with CaO deposits. Oxid. Met. 2015, 84, 185-209. [CrossRef]

8. Salam, S.; Hou, P.Y.; Zhang, Y.D.; Wang, H.F.; Zhang, C.; Yang, Z.G. Compositional effects on the high-temperature oxidation lifetime of MCrAlY type coating alloys. Corros. Sci. 2015, 95, 143-151. [CrossRef]

9. Guo, M.H.; Wang, Q.M.; Gong, J.; Sun, C.; Huang, R.F.; Wen, L.S. Oxidation and hot corrosion behavior of gradient NiCoCrAlYSiB coatings deposited by a combination of arc ion plating and magnetron sputtering techniques. Corros. Sci. 2006, 48, $2750-2764$. [CrossRef]

10. Peng, X.; Jiang, S.; Gong, J. Preparation and hot corrosion behavior of a NiCrAlY + AlNiY composite coating. J. Mater. Sci. Technol. 2016, 32, 587-592. [CrossRef]

11. Lin, H.; Liang, W.; Jia, Y. Effect of AlY gradient coating on hot corrosion resistance of $\gamma$-TiAl alloy at different temperatures. Appl. Surf. Sci. 2019, 487, 868-875. [CrossRef]

12. Jiang, S.M.; Peng, X.; Bao, Z.B. Preparation and hot corrosion behaviour of a MCrAlY + AlSiY composite coating. Corros. Sci. 2008, 50, 3213-3220. [CrossRef]

13. Ma, J.; Jiang, S.M.; Li, H.Q.; Wang, W.X.; Gong, J.; Sun, C. Microstructure and oxidation behaviour of an AlSiY/NiCrAlYSi composite coating at $1150^{\circ} \mathrm{C}$. Corros. Sci. 2011, 53, 1417-1423. [CrossRef]

14. Ma, J.; Jiang, S.M.; Gong, J. Hot corrosion properties of composite coatings in the presence of $\mathrm{NaCl}$ at 700 and $900{ }^{\circ} \mathrm{C}$. Corros. Sci. 2013, 70, 29-36. [CrossRef]

15. Ma, J.; Jiang, S.M.; Gong, J. Behaviour and mechanisms of alkali-sulphate-induced hot corrosion on composite coatings at $900{ }^{\circ} \mathrm{C}$. Corros. Sci. 2012, 58, 251-259. [CrossRef]

16. Wang, Q.; Wu, W.Y.; Jiang, M.Y. Improved oxidation performance of TiAl alloy by a novel Al-Si composite coating. Surf. Coat. Technol. 2020, 381, 125-126. [CrossRef]

17. He, J.; Guo, H.; Zhang, Y.; Gong, S. Improved hot-corrosion resistance of Si/Cr co-doped NiAlDy alloy in simulative sea-based engine environment. Corros. Sci. 2014, 85, 232-240. [CrossRef]

18. Bobzin, K.; Brögelmann, T.; Kalscheuer, C. Al-Si and Al-Si-Y coatings deposited by HS-PVD for the oxidation protection of $\gamma$-TiAl. Surf. Coat. Technol. 2018, 350, 587-595. [CrossRef]

19. Liu, R.D.; Jiang, S.M.; Yu, H.J. Preparation and hot corrosion behaviour of Pt modified AlSiY coating on a Ni-based superalloy. Corros. Sci. 2016, 104, 162-172. [CrossRef]

20. Warzecha, M.; Köhl, D.; Wuttig, M. Ion beam assisted sputter deposition of ZnO for silicon thin-film solar cells. J. Phys. D Appl. Phys. 2014, 47, 105202. [CrossRef]

21. Mao, S.; Yang, H.; Li, J. Corrosion properties of aluminium coatings deposited on sintered NdFeB by ion-beam-assisted deposition. Appl. Surf. Sci. 2011, 257, 5581-5585. [CrossRef]

22. Mao, S.; Xie, T.; Zheng, B. Structures and properties of sintered NdFeB coated with IBAD-Al/ $\mathrm{Al}_{2} \mathrm{O}_{3}$ multilayers. Surf. Coat. Technol. 2012, 207, 149-154. [CrossRef]

23. Jung, Y.I.; Lee, J.S.; Park, J.Y. Ion-beam assisted deposition of coating interlayers for the joining of Be/CuCrZr. Fusion Eng. Des. 2010, 85, 1689-1692. [CrossRef]

24. Ma, J.; Jiang, S.M.; Gong, J. Composite coatings with and without an in situ forming Cr-based interlayer: Preparation and oxidation behaviour. Corros. Sci. 2011, 53, 2894-2901. [CrossRef]

25. Zheng, D.; Zhu, S.; Wang, F. The influence of TiAlN and enamel coatings on the corrosion behavior of Ti6Al4V alloy in the presence of solid $\mathrm{NaCl}$ deposit and water vapor at $450^{\circ} \mathrm{C}$. Surf. Coat. Technol. 2007, 201, 5859-5864. [CrossRef]

26. Ciszak, C.; Popa, I.; Brossard, J.-M.; Monceau, D.; Chevalier, S. NaCl induced corrosion of Ti-6Al-4V alloy at high temperature. Corros. Sci. 2016, 110, 91-104. [CrossRef] 